Saad Awad Abdelrahman, Mohamed El-Sayed Gomaa Samra, heat transfer enhancement and air pollution reduction of exhaust gas stream through swirling recuperator joined with a cyclone-scrubber, pp.1549 - 1563

\title{
HEAT TRANSFER ENHANCEMENT AND AIR POLLUTION REDUCTION OF EXHAUST GAS STREAM THROUGH SWIRLING RECUPERATOR JOINED WITH A CYCLONE-SCRUBBER
}

\author{
Saad Awad Abdelrahman *, 1 , Mohamed El-Sayed Gomaa Samra ${ }^{2}$ \\ 1Mech. Science, Eng., Dept., The specialized Studies Academy, Ministry of Higher Education. \\ 2 Power Meh.l Eng. , Technology Depart., The Specialized Studies Academy, Worker University \\ Ministry of Higher education .
}

Received 12 June 2013 accepted 26 July 2013

\begin{abstract}
In the present work, the heat transfer enhancement and air pollution reduction of exhaust gas stream through swirling recuperator fitted with a cyclone-scrubber are investigated respectively. The scrubbing works via the contact of target compounds or particulate matter with the scrubbing solution. Solutions were the water and the liquid solution (sodium carbonize + lemon salt) respectively. The results are compared with the same one with plain tubes recuperator. The twisted - tapes is optimized at twist ratios $\mathrm{Y}=0.59$ for the outer tube and $\mathrm{Y}=0.74$ for the inner tube. The rod of twisted tape is fixed on bearings to reduce pressure drop by the rotation. The experiments were carried out at Reynolds number from 8000 to 35000 of cold air enters the heat exchanger at $20^{\circ} \mathrm{C}$ while the hot gases enter at $700{ }^{\circ} \mathrm{C}$. The experimental results indicated that the increase in heat transfer rate of the swirling flow is greater than its respective value of plain flow. The maximum mean Nusselt number increased by $181 \%$ than that of plain tube recuperator. The effects of the twisted tape on the heat transfer enhancement efficiency are also investigated. In the other side, the pollution of exhaust gases is greatly reduced by passing exhaust gases into cyclone-scrubber. The results indicated that the concentration of the poisonous gases flow out the cyclone-scrubber decreases by increasing the air velocity. A comparison results between the use of cyclone scrubber by water spray and chemical solution are investigated.
\end{abstract}

Keywords: Heat transfer, Swirling flow, Recuperator, Cyclon-Scrubber.

\section{Introduction}

At present, the technology of twisted -tape insert is widely used in various industries. Insertion of twisted tapes in a tube provides a simple passive technique for enhancing the convective heat transfer by introducing swirl into the bulk flow and by disrupting the boundary layer at the tube surface due to repeated changes in the surface geometry. Therefore, the swirling flow inside the tubes and around the tubes walls will decrease the velocity of fluid flow and increase the turbulent boundary layers of flow. These occur by using a twisted-tape device inserted in tubes. It has been induce turbulence and superimpose vortex motion (swirl flow) causing boundary layers and consequently resulting high heat transfer and high Nusselt number.

Many researchers have investigated the effect of geometry of twisted- tape on heat transfer and friction factor in circular or rectangular smooth tubes in experimental and theoretical studies. Date and Saha [1] predicted numerically high friction and heat transfer

Corresponding author.

E-mail address: saadawad336@yahoo.com 
Saad Awad Abdelrahman, Mohamed El-Sayed Gomaa Samra, heat transfer enhancement and air pollution reduction of exhaust gas stream through swirling recuperator joined with a cyclone-scrubber, pp.1549 - 1563

characteristics for laminar flow in inner circular cylinder fitted with regularly spaced twisted-tape elements. Bhadsavle [2] studied experimentally pressure drop characteristics of laminar and turbulent flow through a square duct fitted with full length of twisted tapes. Chang and Dhir [3] studied mechanisms of heat transfer enhancement and slowed decay of swirl in tubes using tangential injection. Yildiz et al. [4] studied the influence of fluid rotation on the heat transfer and pressure drop in double-pipe heat exchangers.

AL-Fahed et al. [5] studied the pressure drop and heat transfer comparison for both micro-fin tube and twisted-tape inserted in laminar flow. They found that the tight-fit tape gives a better performance over the loose-fit tape. Yilmaz et al . [6] studied the enhancement of heat transfer by turbulent decaying swirl flow. Kumar and Prasad [7] reported the improved solar collectors of water heating types by means of twisted tapes inserted in the water flow tubes. Drmus et al. [8] investigated the heat transfer and pressure drop in a concentric heat exchanger with snail entrance. The results showed that the decaying and snail swirl of the heat transfer coefficient and pressure drop decreases with the axial distance, while for the continuous swirl flow the heat transfer coefficient and pressure drop are rather constant. Ray and Date [9] presented experimentally a correlations of friction factor and heat transfer characteristics for flow through square duct with twisted tape insert. Seo and Hyung [10] studied the direct numerical simulation of turbulent concentric annular pipe flow. The results showed that the turbulent thermal structures near the outer wall were more activated than those near the inner wall, which may be attributed to the different vortex regeneration processes between the inner and outer walls. Mahmoud Farzaneh et al. [11] studied the effects of swirl on the flow rate and heat transfer in a preswirl rotating-disc system. Chang [12] presented an experimental study on turbulent swirling flow in a cylindrical annuli by using the PIV technique. The results showed that the velocity vector had negative values near the convex tube and then the vectors changed to positive velocity with decaying swirl intensity and the axial turbulence intensities reached to a maximum value near the concave wall. Watcharin [13] studied the effect of twisted -tape inserts on heat transfer in a tube. The results revealed that the increase in heat transfer rate was found to be strongly influenced by twisted tape-induced swirl or vortex motion and Nusselt numbers increased higher than that for the plain tube. Jawarneh [14] studied the analytical approximate solution for decaying laminar swirling flows within a narrow annulus. The results indicated that the swirl velocity exhibits a Hagen-Poiseuille flow profiles and these profiles decay gradually down stream because of friction. The pressure drop was non linear and depends on the inlet swirl Reynolds number. Ayinde [15] studied a generalized relationship for swirl decay in laminar pipe flow. The result was a generalized relationship for swirl decay as a function of these parameters as the flow Reynolds number, the distance from the pipe inlet, the pipe diameter and the nature of inlet swirl.

In pressent study, the heat transfer enhancement and air pollution reduction of flow through swirling recuperator cylinder fitted with a cyclone-scrubber are investigated, respectively.The results are compared with the same one with plain tubes recuperator. The

Journal of Engineering Sciences, Assiut University, Faculty of Engineering, Vol. 41, No. 4, July, 2013,E-mail address: jes@aun.edu.eg 
Saad Awad Abdelrahman, Mohamed El-Sayed Gomaa Samra, heat transfer enhancement and air pollution reduction of exhaust gas stream through swirling recuperator joined with a cyclone-scrubber, pp.1549 - 1563

experimental design was optimized by using a rotary twist tape with rod inserted in all length of the tubes, also the twist ratio (twist-tape pitch to pipe diameter) was chosen less than one $(\mathrm{Y}<1.0)$ to get benefit of a higher heat transfer rate and reduction of pressure drop in comparison with other researches. So, Ygas $=0.74$ for inner tube and Yair $=0.59$ for outer tube of recuperator are chosen according to the available materials, dimensions and fabrication of twisted-tape inserted in tubes. The experiments are carried out at the ranges of Reynolds number from 8000 to 35800 of cold air. Reduction of air pollution from cyclone-scrubber also is investigated. The pollution of exhaust gases is greatly reduced by passing exhaust gasses into cyclone-scrubber with twisted rings and liquid solution are pumped in a closed system. The solutions were the water and the liquid solution (sodium carbonize + lemon salt) respectively.

\section{Experimental test rig}

Figure 1 shows photography the overall view of the complete test rig and Figs. 2-4 show a schematic view of experimental setup and a concentric double cylinder heat exchanger (swirling recuperator cylinder) fitted with a cyclone-scrubber. Figure 2 shows the experimental test rig of plain flow. The rod with twisted-tape is fixed on ball bearings at the ends of tube to rotate in the inner tube by the swirling flow of hot gases. The outer tube is a plain tube used for plain flow first of cold air. After the first test of the plain flow inside the outer tube of recuperate or the twisted-tape is welded in the outer tube to make a swirling flow for cold air as shown in Figure 3. The test rig is designed and manufactured from steel tubes. The outer tube of recuperator has $300 \mathrm{~mm}$ diameter, $800 \mathrm{~mm}$ length and 4 $\mathrm{mm}$ thickness. The inner tube of recuperator has $200 \mathrm{~mm}$ diameter, $1000 \mathrm{~mm}$ length and 4 $\mathrm{mm}$ thickness. The twisted tapes with rod are fabricated from steel strips of thickness 2.0 $\mathrm{mm}, 60 \mathrm{~mm}$ width, twisted-tape angle at 60 degree and welded around the rod of $25 \mathrm{~mm}$ diameter. The twisted-tapes with rod was inserted inside the inner tube with $\mathrm{Y}=0.74$ and fixed on ball bearings from two sides of tube to rotate the rod with twisted-tape inside the inner tube of recuperator to eliminate the pressure drop. The twisted-tapes welded about its longitudinal axis of outer tube with opposite direction to the other twisted-tape of inner tube for counter flow at twist ratio $\mathrm{Y}=0.59$. The annulus (flow passage) is swirling throughout the outer tube. Exhaust is supplied from the burner of a capacity of $47 \mathrm{~kW}$. Exhaust gases is supplied to the inner tube of recuperator at temperature $700{ }^{\circ} \mathrm{C}$. The cold air enters at different inlet velocities by air compressor to the outer tube at ambient temperature $20{ }^{\circ} \mathrm{C}$. The test rig is controlled by measuring devices for temperatures, velocities and pressure drop. Twenty-eight pre-calibrated K-type thermocouples of $0.3 \mathrm{~mm}$ wire diameter, of $1 \mathrm{~mm}$ probe diameter and of $20 \mathrm{~ms}$ response time were used to measure the temperature at definite locations. Testo 415 thermal anemometer was used to measure the air velocity. All pressure readings were taken under isothermal conditions by installing a pressure gage from inlet and outlet (air and exhaust gas) for measuring the pressure drop between the inlet and outlet. A combined type of cyclone-scrubber as shown in Fig. 1 is designed for cleaning and filtration the exhaust gases by oxidation the carbon dioxide

Journal of Engineering Sciences, Assiut University, Faculty of Engineering, Vol. 41, No. 4, July, 2013, E-mail address: jes@aun.edu.eg 
Saad Awad Abdelrahman, Mohamed El-Sayed Gomaa Samra, heat transfer enhancement and air pollution reduction of exhaust gas stream through swirling recuperator joined with a cyclone-scrubber, pp.1549 - 1563

(CO2) and absorption the gaseous contaminant and separation the particulates from the exhaust gases and dissolving SO2 to the solution. It is a vertical cylinder (cyclone) of 450 $\mathrm{mm}$ diameter and $650 \mathrm{~mm}$ high and has two cones, one in the top and the other in the bottom. The top of the cone has $430 \mathrm{~mm}$ high and the bottom of the cone has $220 \mathrm{~mm}$ high, $75 \mathrm{~mm}$ diameter. A swirling tape $70 \mathrm{~mm}$ width and $1.5 \mathrm{~mm}$ thickness is fitted inside the vertical cyclone of diameter $380 \mathrm{~mm}$. The tapes fitted and welded at inclined angle of $60^{\circ}$. When the flow of exhaust gases inlet to the cyclone - scrubber the swirling tapes directed the gases to flow tangentially and swirling inside the cyclone-scrubber. The scrubbing works via the contact of target compounds or particulate matter with the scrubbing solution. Solutions were the water as in Fig. 3 and the liquid solution (sodium carbonize + lemon salt) as in Fig.4 are used respectively. The liquid solution (sodium carbonize + lemon salt) circulated with water pump in closed system and sprayed from the drilled galvanized steel pipe of $13 \mathrm{~mm}$ diameter and $500 \mathrm{~mm}$ length fixed inside the cyclonescrubber to dissolve SO2 from the exhaust gases and takeout from the drainage tank. Fresh air is added from small nozzle $3 \mathrm{~mm}$ diameter to flow the air inside the cyclone-scrubber to oxide the carbon $(\mathrm{CO})$ to $\mathrm{CO} 2$. A Lancôme portable flue gas analyzers is used to measure $\mathrm{CO}, \mathrm{SO} 2$ and NOX.

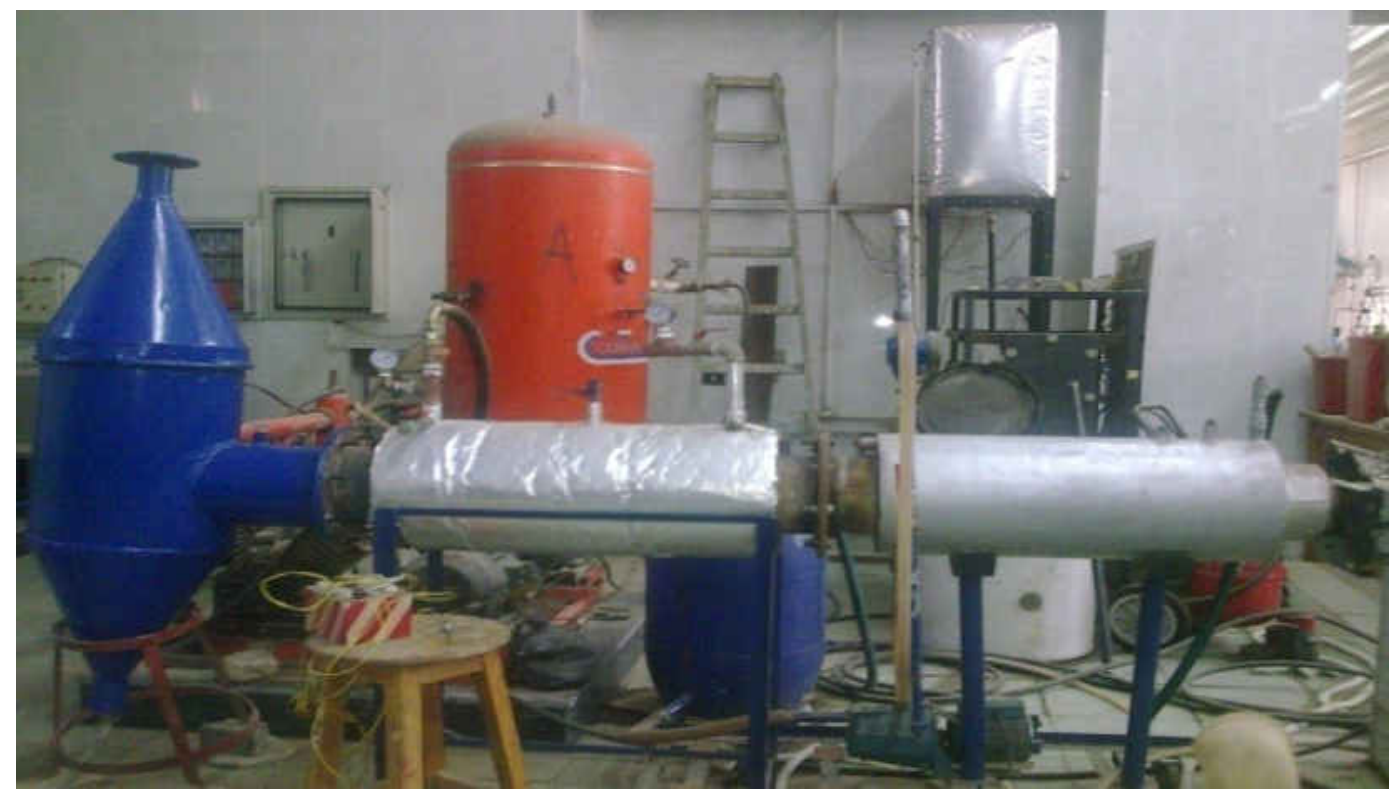

Fig.1. Overall view of the complete test rig

Journal of Engineering Sciences, Assiut University, Faculty of Engineering, Vol. 41, No. 4, July, 2013,E-mail address: jes@aun.edu.eg 
Saad Awad Abdelrahman, Mohamed El-Sayed Gomaa Samra, heat transfer enhancement and air pollution reduction of exhaust gas stream through swirling recuperator joined with a cyclone-scrubber, pp. $1549-1563$

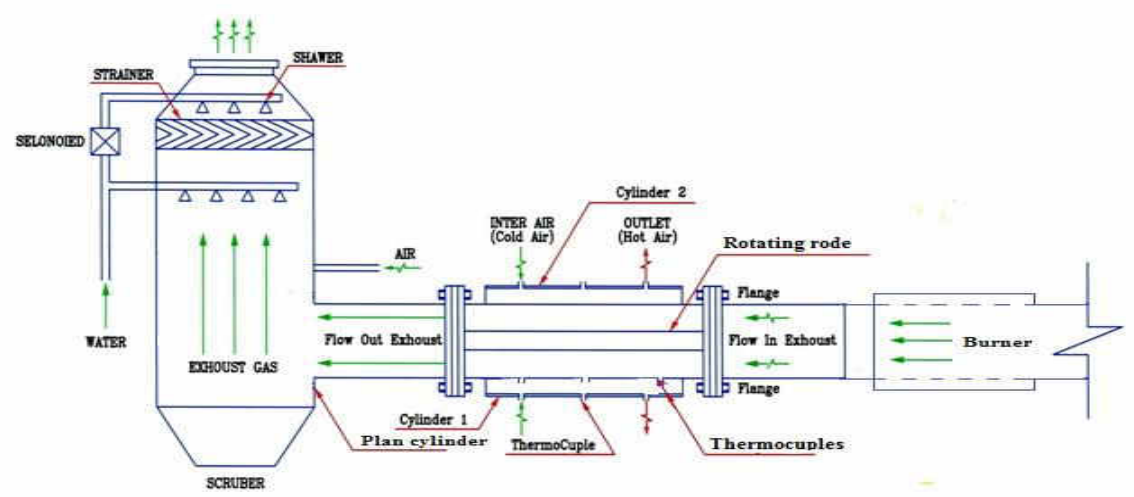

Fig. 2. Experimental test rig of plain flow in inner and outer tubes recuperator

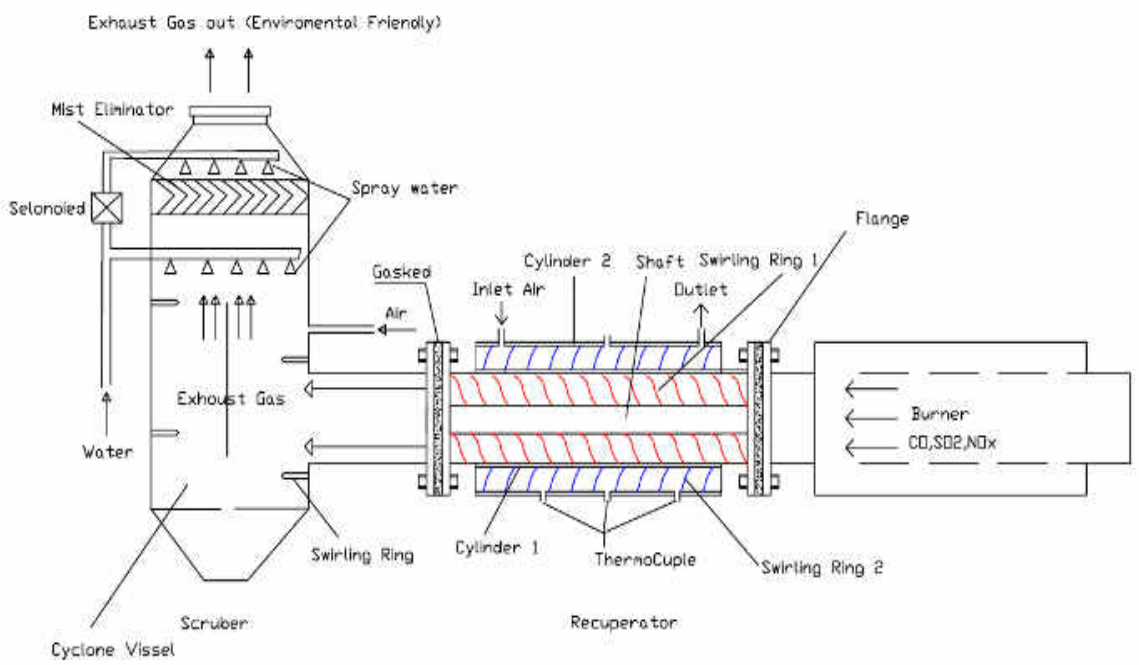

Fig.3. Experimental test rig of swirling flow in inner and outer tubes recuperator

Journal of Engineering Sciences, Assiut University, Faculty of Engineering, Vol. 41, No. 4, July, 2013,E-mail address: jes@aun.edu.eg 
Saad Awad Abdelrahman, Mohamed El-Sayed Gomaa Samra, heat transfer enhancement and air pollution reduction of exhaust gas stream through swirling recuperator joined with a cyclone-scrubber, pp.1549 - 1563

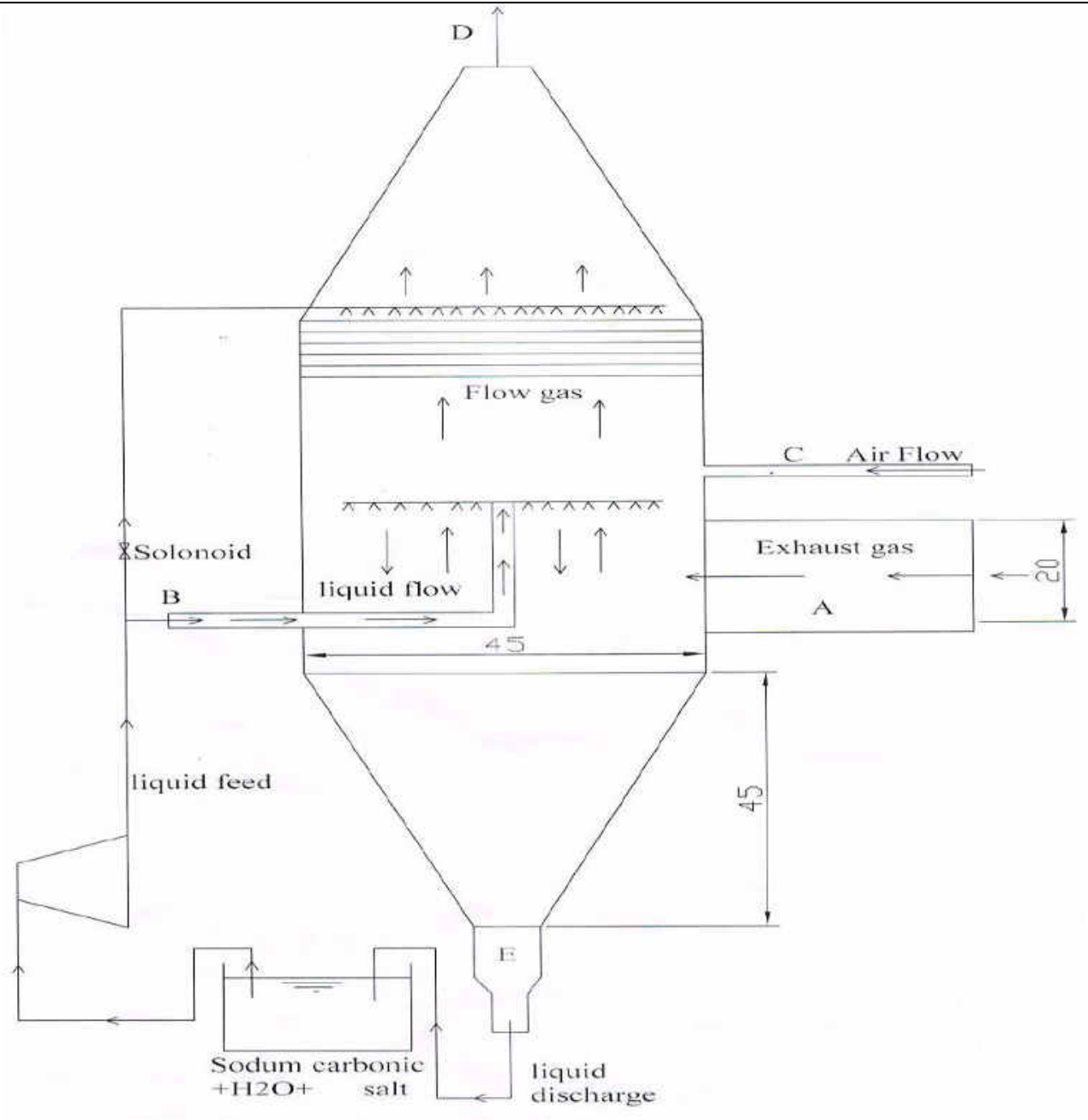

Fig.4. The cyclone-scrubber with the liquid solution (sodium carbonize + lemon salt)

\section{Test procedure}

In the current experimental work, four sets of experiments were carried out as follows:

(1) In the first set of experiments, the recuperator is working without twisted-tapes with rod, i.e (plain tubes) as shown in Fig. 1. Exhaust gases is supplied to the inner tube of recuperator at inlet temperature $700^{\circ} \mathrm{C}$ and at constant velocity. The cold air enters to the outer tube at ambient temperature $20^{\circ} \mathrm{C}$ and different inlet velocities. The heat is transferred between hot gases and cold air by convection. The measuring results of pressure drop, temperatures, and velocities at the inlet and outlet of cold air and also for hot gases of recuperator are measured and recorded under isothermal conditions at each

Journal of Engineering Sciences, Assiut University, Faculty of Engineering, Vol. 41, No. 4, July, 2013,E-mail address: jes@aun.edu.eg 
Saad Awad Abdelrahman, Mohamed El-Sayed Gomaa Samra, heat transfer enhancement and air pollution reduction of exhaust gas stream through swirling recuperator joined with a cyclone-scrubber, pp.1549 - 1563

value of inlet velocity and pressure drop of cold air. The inlet and outlet temperatures of both hot gases and warm air are measured by thermocouples type (k). The velocities of warm and cold air are measured by hot wire Anemometer model (testo 415). The temperatures and velocities are measured at different points to find out the average amounts of results. These results are used as input data to the calculation program to get Nusselt number $(\mathrm{Nu})$, Reynold number $(\mathrm{Re})$, convection heat transfer coefficient $(\mathrm{h})$, friction factor $(f)$ and enhanced effectiveness of recuperator $(\eta)$.

(2) In the second set of experiments, the twisted- tapes with rod were inserted and welded in the inner tube of recuperator and fixed on ball bearings at two ends of inner tube as shown in Fig. 2. The twisted-tapes welded about its longitudinal axis of outer tube with opposite direction to the other twisted-tape of inner tube for counter flow. The recuperator was working and tested at the same isothermal condition with the same measuring devices and same procedures for hot gases and cold air. The measuring results are recorded and used as input data to the calculation program. The program was based on the given equations [13].

(3) In the third set of experiments, the inlet swirling exhaust gas enters at the middle of the scrubber into the water sprays and strainer to remove pollutants from gas stream and dust particles.

(4) In the last set of experiments, the concentration of the poisonous gases flow out the cyclone-scrubber decreases by scrubbing with a liquid solution. The solutions was (Sodium Carbonate, Na2 CO3 and CIRIC acid from lemon salt.

A Lancôme III portable flue gas analyzers is used to measure $\mathrm{CO}, \mathrm{SO} 2$ and NOX..

Cyclone Scrubber passes through the following five steps:

Step 1: Determine the concentration of the exhaust gas without scrubbing and determine PH.

Step 2: $\quad$ Determine the concentration of the exhaust gas by scrubbing only.

Step 3: Determine the concentration of the exhaust gas by scrubbing with the water spray.

Step 4: Determine the concentration of the exhaust gas by scrubbing with the solution

Step 5: $\quad$ Inserting pressurized air at 2 pa to the scrubbed solution and determine PH of the solution and increases the amount of pressurized air to 5 pa.

The exhaust gases swirl and wash through strainers at three stages with different sizes $1.5 \mathrm{~mm} 2$, $1.0 \mathrm{~mm} 2$ and $0.4 \mathrm{~mm} 2$ to separate the ashes particles, and takeout from the drainage tank.

The cyclone-scrubber is controlled by temperature and gas analysis measuring devices to measure the inlet and outlet temperatures and percentage of exhaust gases analysis. The exhaust gases flow out the cyclone- scrubber are measured and recorded.

\section{Data reduction}

The heat transfer rate of hot exhaust gases in the inner tube of concentric double tubes heat exchanger (swirling recuperator) expressed as [13]:

$$
\mathrm{Q}=\mathrm{mCp}[\mathrm{Tho}-\mathrm{Thi}] \quad \mathrm{W}
$$

Journal of Engineering Sciences, Assiut University, Faculty of Engineering, Vol. 41, No. 4, July, 2013,E-mail address: jes@aun.edu.eg 
Saad Awad Abdelrahman, Mohamed El-Sayed Gomaa Samra, heat transfer enhancement and air pollution reduction of exhaust gas stream through swirling recuperator joined with a cyclone-scrubber, pp. $1549-1563$

The heat transfer of the cold air for the outer tube is calculated by

$$
\begin{aligned}
& \mathrm{Q}=\mathrm{hA}[\mathrm{Tw}-\mathrm{Tb}] \\
& \mathrm{Tb}=[\mathrm{To}+\mathrm{Ti}] / 2 \\
& \mathrm{Tw} \geq
\end{aligned}
$$

Where Tw is the average local wall temperatures and measured at the outer wall surface of the inner tube at four points, lined between the inlet and exit of the inner tubes. The average heat transfer coefficient is calculated from the energy balance and estimated as follows:

$$
\mathrm{h}=\mathrm{m} \mathrm{Cp}[\mathrm{To}-\mathrm{Ti}] / \mathrm{A}[\mathrm{Tw}-\mathrm{Tb}] \quad \mathrm{w} / \mathrm{m} 2 . \mathrm{k}
$$

The mean value of the Nusselt number is calculated based on the mean wall temperature $\mathrm{Tw}$ and mean air temperature (Tmean ) measured at six points on the outer tube of recuperator.

$$
\mathrm{Nu}=\mathrm{h} . \mathrm{D} / \mathrm{K}
$$

Where, $\mathrm{h}$ and $\mathrm{k}$ are the mean heat transfer coefficient and mean thermal conductivity of the air respectively at all thermocouple location. The local thermal conductivity $k$ of the air is calculated from the fluid properties at the local mean bulk fluid temperature.

The Reynolds number is calculated based on the volume flow rate of cold air through the test section at different velocities .

$$
\mathrm{Re}=\mathrm{Q} \cdot \mathrm{D} / \mathrm{v} \cdot \mathrm{A}=\mathrm{V} \cdot \mathrm{D} / \mathrm{v}
$$

where $\mathrm{v}$ is the kinematics viscosity of the working fluid, and $\mathrm{V}$ is the average velocity of cold air.

Friction factor can be expressed as follows:

$$
f=\Delta \mathrm{p} /(\mathrm{L} / \mathrm{D})(\rho \mathrm{V} 2 / 2)
$$

The enhanced effectiveness $(\eta)$ at constant pumping power is the ratio of the convective heat transfer coefficient of the tube with twisted tape to the plain tube as follows:

$$
\begin{aligned}
& \eta=\mathrm{h} \text { swirl } / \mathrm{h} \text { plain } \\
& \eta=0.836 \operatorname{Re} 0.17 \mathrm{Y}-0.38 \\
& \text { where }: \\
& \text { Yair }=\text { pitch / cylider diameter }=0.59
\end{aligned}
$$

Journal of Engineering Sciences, Assiut University, Faculty of Engineering, Vol. 41, No. 4, July, 2013,E-mail address: jes@aun.edu.eg 
Saad Awad Abdelrahman, Mohamed El-Sayed Gomaa Samra, heat transfer enhancement and air pollution reduction of exhaust gas stream through swirling recuperator joined with a cyclone-scrubber, pp.1549 - 1563

$$
\text { Ygases }=\text { pitch } / \text { cylider diameter }=0.74
$$

\section{Results and discussion}

Figure 5 shows that the heat transfer coefficient by using the full-length twisted tape with rod inserted in a co-axial tube recuperator at small twist ratio $(Y=0.59)$. It is found that the twisted-tape fitted gives higher heat transfer rate than that of the plain tube. It can be attributed that the use of full-length twisted-tape insert can cause the swirl and pressure gradient in the radial direction. The boundary layer along the tube wall would be thinner with the increase of radial swirl and pressure resulting in more heat flow through the fluid. Further more, the swirl enhances the flow turbulence, which led to even better convection heat transfer.

Figure 6 shows that the increase in Reynolds numbers leads to an increase in Nusselts numbers for the swirl flow and plain flow. The corresponding increase of mean Nusselt numbers by using the twisted-tape with rotary rod inside tube recuperator is higher up to $181 \%$ than that of plain tube recuperator.

Figure 7 shows that the use of the small twist ratio $(Y=0.59)$ leads to increase the enhanced effectiveness at the same Reynolds numbers of plain tube recuperator. The performance improved in the intervals of Reynolds number. Thus the use of various styles of twisted-taps inserted inside the inner tube and welded along the outer tube to reduce the pressure drop and increase the heat transfer rate.

Figure 8 shows that pressure drop from the twisted-tape with rotary rod inserted in recuperator decreases at low Reynolds numbers due to weak swirling flow but increases substantially at higher values of Reynolds number. It can be seen that the trend of pressure drop for the plain flow is similar to that of the swirl flow. The pressure loss for the tube with the tape is substantially higher than that for the plain tube because of a higher surface area and the dissipation of dynamic pressure of the fluid at high viscosity loss near the tube wall. Moreover, the pressure loss had high possibility to occur by the interaction of pressure forces and inertial forces in the boundary layer. Also, the flow velocity is larger since the motion is not in an axial direction.

Figure 9 shows the comparison between the friction factors of swirling flow and that of plain flow recuperator. The trend of results agrees well with the correlations of swirl flow and plain flow that is generally higher at low Reynolds numbers.

The exhaust gases flow out the cyclone- scrubber with low pollution. Figure 10 shows the variation of the gases emission $(\mathrm{NOx}, \mathrm{SO} 2, \mathrm{CO})$ versus the air velocity at 2 pa. The results indicated that the concentration of the poisonous gasses flow out the cyclonescrubber decreases by increasing the air velocity.

It is found that the concentration of the poisonous gases decrease from step 1 to step 4 , $\mathrm{CO}=32 \%$ and $\mathrm{SO} 2=83 \%$ and $\mathrm{NOX}=36 \%$ but by increasing the amount of pressurized air, the amount of $\mathrm{CO} 2$ and NOX increases at(5psi).PH at step1 $=3$ and at step $4=6$. The solvant used for the scrubber (Na2CO3 and Citric acid), Scrubbing:Pressurized air (2 pa) not more, PH (3-6), Concentretion (10-3-10-6) Mole/ Litre. CO and CO2 and NOX

Journal of Engineering Sciences, Assiut University, Faculty of Engineering, Vol. 41, No. 4, July, 2013,E-mail address: jes@aun.edu.eg 
Saad Awad Abdelrahman, Mohamed El-Sayed Gomaa Samra, heat transfer enhancement and air pollution reduction of exhaust gas stream through swirling recuperator joined with a cyclone-scrubber, pp.1549 - 1563

decrease. All these conditions lead to decrease the amount of poisonous gas, cardiac and respiratory diseases.

Figure 11 shows Comparison between the concentration SO2 and NOX emissions by using the cyclone scrubber with water spray and chemical solution respectively at various pressures. The results indicated that the concentration of SO2 and NOx flow out the cyclonescrubber decrease higher by using the chemical solution than by using spray water.

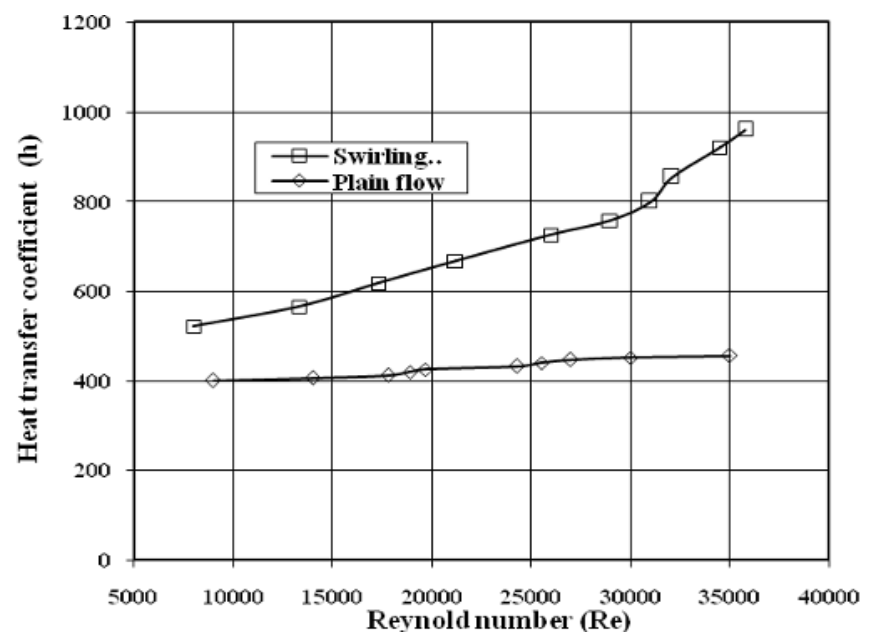

Fig. 5. Experimental heat transfer coefficients of swirling flow recuperator at $Y=0.59$ and plain flow versus Reynolds numbers

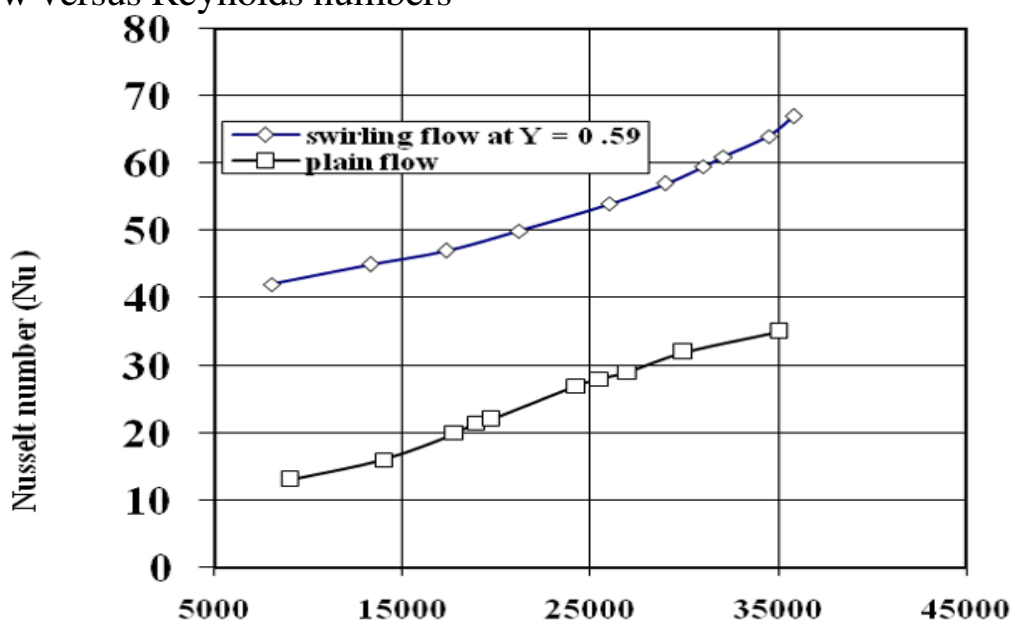

Reynolds number ( Re)

Fig.6. Experimental Nusselt numbers of swirling flow and plain flow versus Reynolds numbers

Journal of Engineering Sciences, Assiut University, Faculty of Engineering, Vol. 41, No. 4, July, 2013,E-mailaddress: jes@aun.edu.eg 
Saad Awad Abdelrahman, Mohamed El-Sayed Gomaa Samra, heat transfer enhancement and air pollution reduction of exhaust gas stream through swirling recuperator joined with a cyclone-scrubber, pp.1549 - 1563

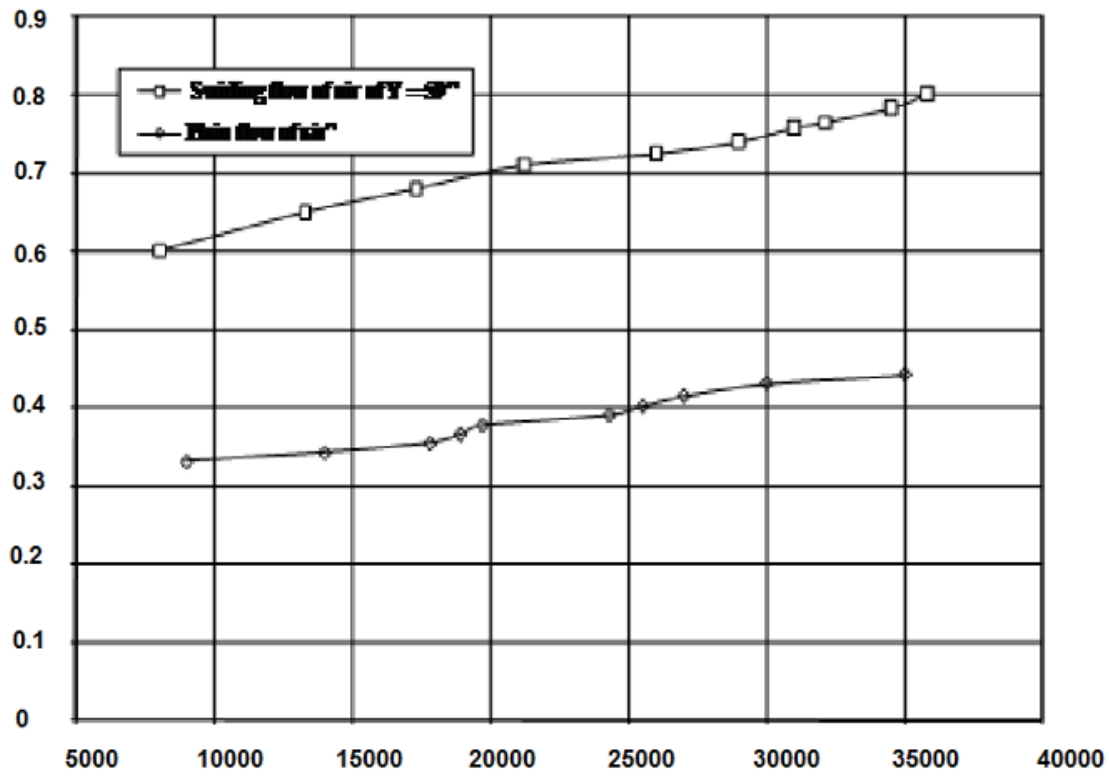

Fig. 7. Variation of enhancement effectiveness of swirling flow at $\mathrm{Y}=0.59$ and plain flow versus Reynolds number

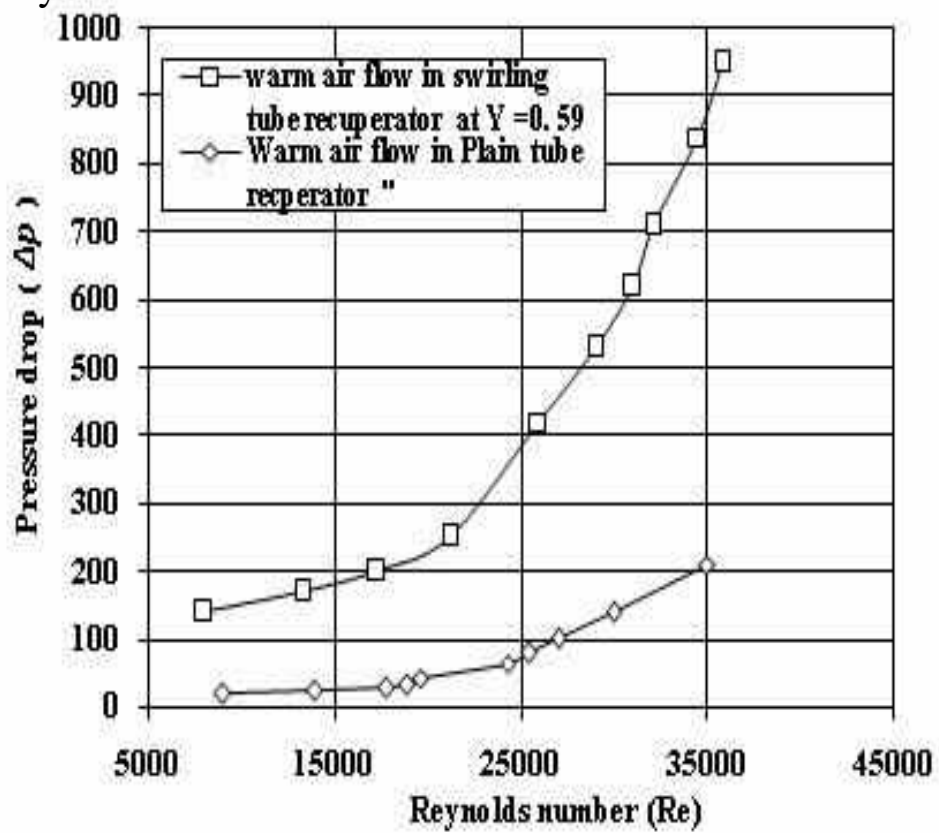

Fig. 8. Experimental pressure drop of swirling flow recuperator at $Y=0.59$ and plain flow versus Reynolds numbers

Journal of Engineering Sciences, Assiut University, Faculty of Engineering, Vol. 41, No. 4, July, 2013,E-mailaddress: jes@aun.edu.eg 
Saad Awad Abdelrahman, Mohamed El-Sayed Gomaa Samra, heat transfer enhancement and air pollution reduction of exhaust gas stream through swirling recuperator joined with a cyclone-scrubber, pp. $1549-1563$

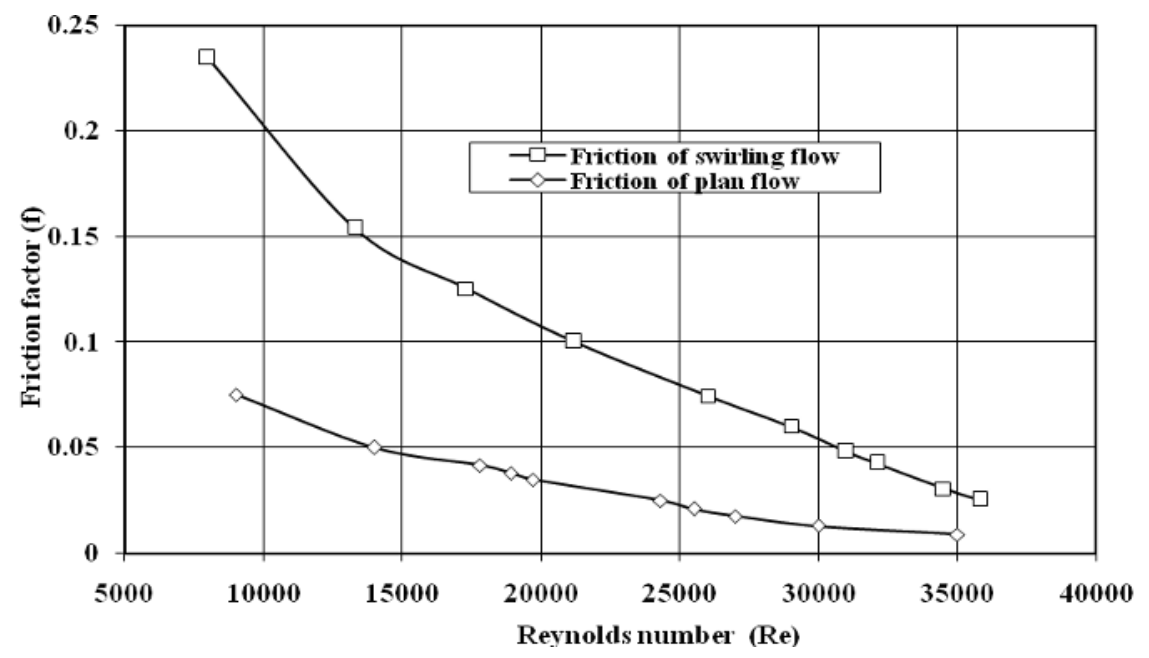

Fig. 9. Friction factor of swirling flow recuperator at $Y=0.59$ and plain flow versus Reynolds numbers

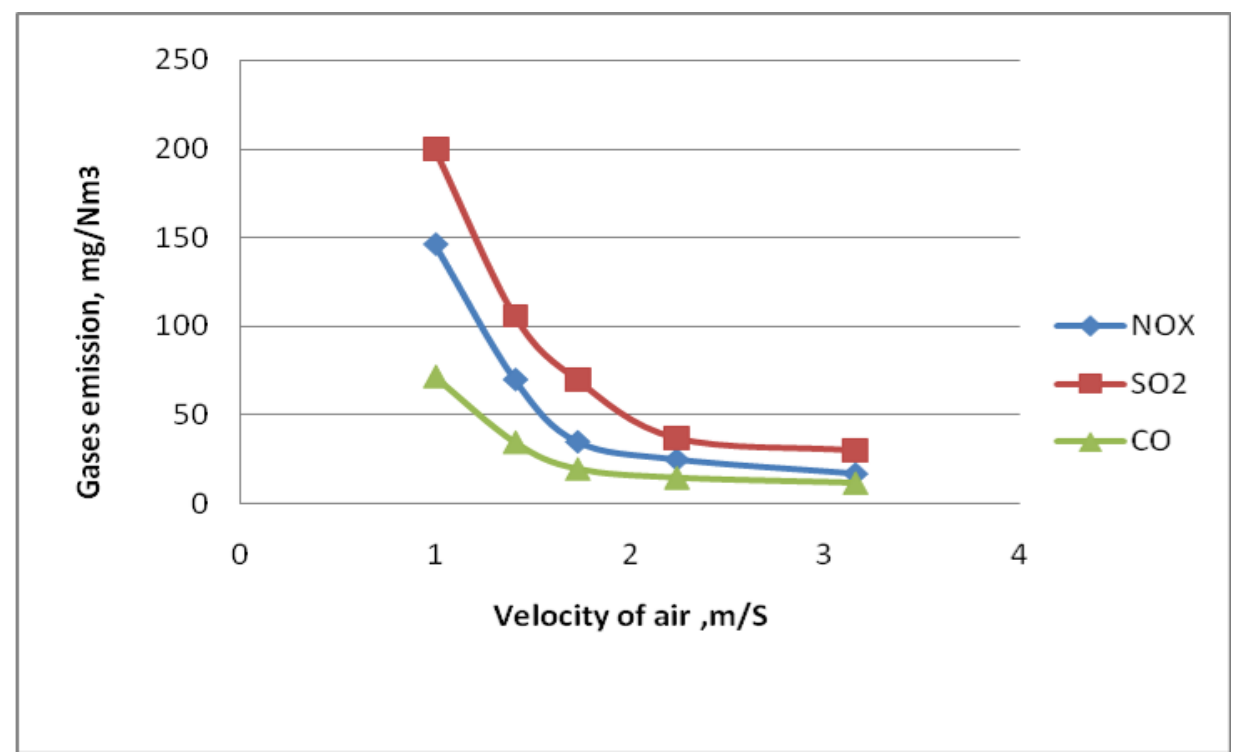

Fig.10. Variation of the gasses emission $(\mathrm{NOx}, \mathrm{SO} 2, \mathrm{CO})$ versus the air velocity at 2 pa

Journal of Engineering Sciences, Assiut University, Faculty of Engineering, Vol. 41, No. 4, July, 2013,E-mailaddress: jes@aun.edu.eg 
Saad Awad Abdelrahman, Mohamed El-Sayed Gomaa Samra, heat transfer enhancement and air pollution reduction of exhaust gas stream through swirling recuperator joined with a cyclone-scrubber, pp.1549 - 1563

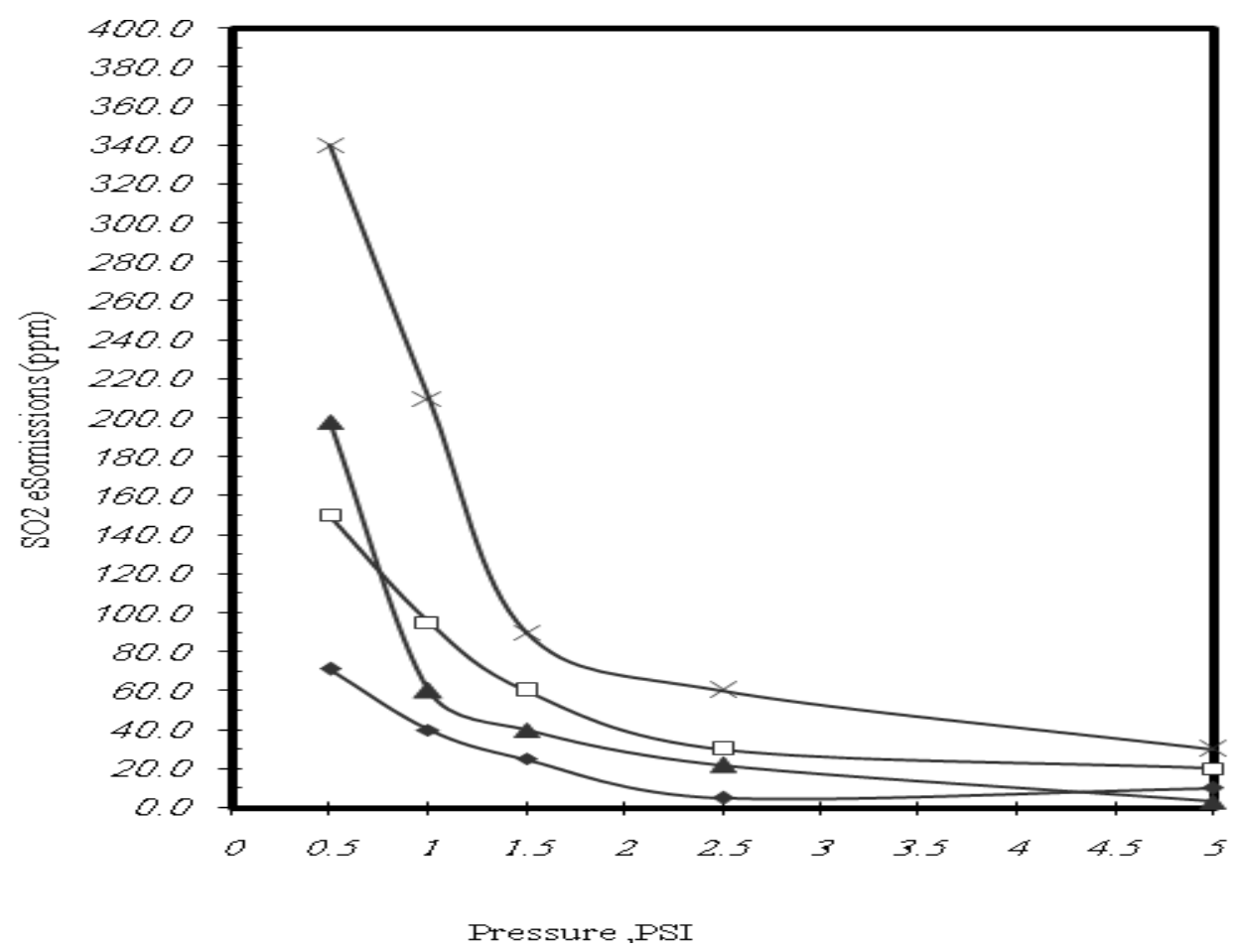

Fig. 11. Comparison between the concentration of SO2 and NOX emissions by using the cyclone scrubber with water spray and chemical solution respectively at various pressures

\section{Conclusions}

An experimental study has been conducted to investigate the enhanced heat transfer by means of twisted-tape with rotary rod inserts in a double tubes recuperator and by using cold air and hot gases as tested fluids. The design is optimized by using a twist tape with rotary rod inserted in all length of the tubes. Also the twist ratio (swing-tape pitch to pipe diameter) was less than one $(Y<1.0)$ for both tubes to get a higher heat transfer rate and reduction of pressure loss in comparison with the plain tube recperator. So, Ygas $=0.74$ for inner tube and Yair $=0.59$ for outer tube recuperator. The present design can improve the heat transfer rate. The enhanced effectiveness and the maximum mean Nusselt number increased by $181 \%$ than that of plain tube recuperator. The enhanced effectiveness, Nusselt number and friction factor decreases by increasing the Reynolds number. Also, they increase with decreasing of the twist ratio. The exhaust gases flow out the cyclone- scrubber with low pollution. The results indicated that the concentration of $\mathrm{SO} 2$ and $\mathrm{NOx}$ flow out the cyclone-scrubber decreases higher by using the chemical solution than by using spray water.

Journal of Engineering Sciences, Assiut University, Faculty of Engineering, Vol. 41, No. 4, July, 2013,E-mail address: jes@aun.edu.eg 
Saad Awad Abdelrahman, Mohamed El-Sayed Gomaa Samra, heat transfer enhancement and air pollution reduction of exhaust gas stream through swirling recuperator joined with a cyclone-scrubber, pp.1549 - 1563

\section{References}

[1] Date, A.W. and Saha, S.K., Numerical prediction of laminar flow and heat transfer in a tube fitted with regularly spaced twisted-tape elements, Int.J. Heat Fluid Flow, 1990, Vol. 11, pp. 346-354.

[2] Bhadsavle, V.S., Pressure drop characteristics of laminar and turbulent flow through a square duct fitted with full length twisted tapes, 1994.

[3] Chang. F.Dhir, V.K, Mechanisms of heat transfer enhancement and slow decay of swirl in tubes using tangential injection. Int J. Heat fluid flow, 1995, Vol 16, pp 78-87.

[4] Yildiz, C, Bicer,Y, Pehivan,D., Influence of fluid rotation on the heat transfer and pressure drop in double-pipe heat exchangers. Appl. Energy,1996, Vol. 54, pp 49-56 .

[5] AL-Fahed, S. Chamra, L..M. and Chakroun, W., Pressure drop and heat transfer comparison for both micro-fin tube and twisted-tape inserted in laminar flow, Exp. Therm.Fluid Sci.,1998, vol. 18, (4), pp. 323-333.

[6] Yilmaz, Enhancement of heat transfer by turbulent decaying swirl flow, Energy Conversion ,1999, Mgmt. Vol. pp1365-1376.

[7] Kumar, A. and Prasad, B.N. , Investigation of twisted tape inserted solar water heaters-heat transfer, friction factor and thermal performance results, Renewable Energy Journal,2000, Vol.19, pp. 379-398.

[8] Drmus, The investigation of heat transfer and pressure drop in a concentric heat exchanger with snail entrance,2002, Vol. 22, pp321-332

[9] Ray,S. and Date, A.W., Friction factor and heat transfer characteristics for flow through square duct with twisted tape insert, Int. J. Heat and mass Transfer,2003, Vol. 46, pp.889902.

[10] Seo Yoon and Hyung Jin , Direct numerical simulation of turbulent concentric annular pipe flow. Part 2; Heat transfer, Int. J. Heat and fluid flow, 2003,Vol 24 ,pp 399-411.

[11] Mahmoud Farzaneh, Michael Wilson and J.Michael Owen, Effects of swirl and flow rate on the flow and heat transfer in a pre-swirl rotating-disc system, Proceedings of the international Gas Turbine congress Tokyo TS-064,2003, pp1-6.

[12] Chang , Experimental study on turbulent swirling flow in a cylindrical annuli by using the PIV technique, Int. J. of Automotive Technology,2004, Vol.5, No.1, pp. 17-22.

[13] Watcharin , Effect of twisted -tape inserts on heat transfer in a tube, International Conference on " Sustainable Energy and Environment", Bangkok, Thailand, A-030(p),2006.

[14] Ali M. Jawarneh , Analytical approximate solution for decaying laminar swirling flows within a narrow annulus, Jordan Journal of mechanical and Industrial Engineering,2008, Vol. 2 .No. 2 , pp101-109.

[15] T.F. Ayinde, A generalized relationship for swirl decay in laminar pipe flow, Indian Academy of Sciences,(Sadhana), 2010, Vol.35 , part2, pp 129-137.

[16] Johim H.linhard, text book of heat and mass transfer, third edition,2008.

[17] Bahrami A, Ghorbani F,Mahjub H ,Aliabadi M."Application of traditional cyclone with spray scrubber to remove airborne silica particles emitted from stone-crushing factories", IndHealt, 2009,pubMed-NCBI.

[18] Environmental Protection Agency, "Wet Scrubber System Study", NTIS Report PB-213016. Research Triangle Park, NC, 1972.

Journal of Engineering Sciences, Assiut University, Faculty of Engineering, Vol. 41, No. 4, July, 2013,E-mail address: jes@aun.edu.eg 
Saad Awad Abdelrahman, Mohamed El-Sayed Gomaa Samra, heat transfer enhancement and air pollution reduction of exhaust gas stream through swirling recuperator joined with a cyclone-scrubber, pp.1549 - 1563

\section{زيادة معدل انتقال الحرارة وتقليل الملوثات لسيل من غاز العادم يمر خلال مبادل حرارى حلزونى متصل بجهاز غسل الغاز لغيل من غاز العات}

\section{الملخص العربى}

فى هذا البحث تم إجراء دراسة عملية على تأثير الحلقات الحلزونية بالمبادل الحرارى على معدل انتقال

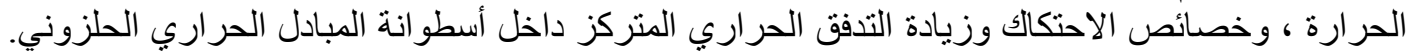

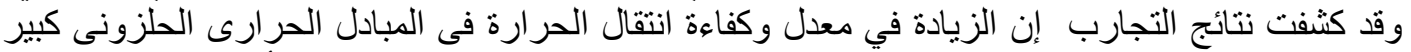

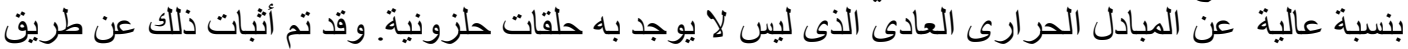

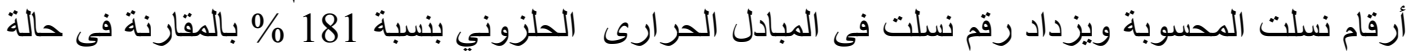

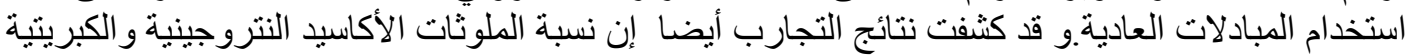

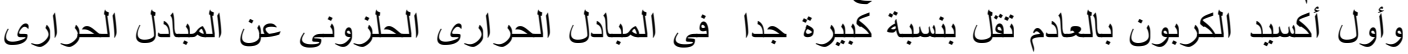

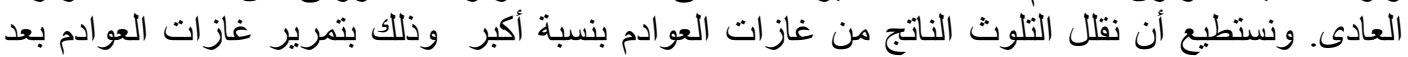

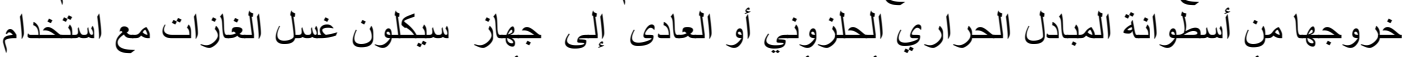

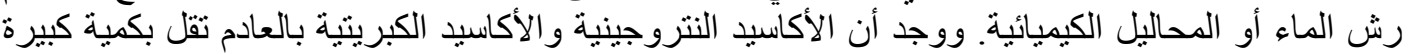
باستخدام المحاليل الكيميائية.

Journal of Engineering Sciences, Assiut University, Faculty of Engineering, Vol. 41, No. 4, July, 2013,E-mail address: jes@aun.edu.eg 